\title{
Enantioselective gold(I)-catalyzed cyclization/intermolecular nucleophilic additions of 1,5-enyne derivatives
}

\author{
Xu Han, ${ }^{\text {a,b }}$ Pascal Retailleau, ${ }^{a}$ Vincent Gandon, ${ }^{* b, c}$ and Arnaud Voituriez*a
}

An enantioselective $\mathrm{Au}(\mathrm{I})$-catalyzed cyclization/nucleophilic addition process is developed, starting from 1,5-enyne substrates. A broad scope of $\mathrm{O}-, \mathrm{N}$ - and $\mathrm{C}$-nucleophiles was introduced in order to provide the corresponding chiral cyclopentene derivatives in moderate to high yields and up to $96: 4$ enantiomeric ratio.

Gold catalysis is known to be a highly powerful tool for the synthesis of polycyclic molecules via cycloisomerization of unsaturated substrates. ${ }^{1}$ Several applications in the synthesis of complex natural products demonstrated the maturity attained nowadays by these methods. ${ }^{1 c}$ Furthermore, the recent development of efficient chiral gold catalysts increased the potential of isolation of enantioenriched molecules. ${ }^{2}$ In the continuation of the development of innovative asymmetric gold-catalysis methodologies, we decided to focus in the present work on the development of 1,5-enyne cyclization processes. $^{3-7}$ These substrates have been much less studied than their 1,6-enyne congeners. ${ }^{1,8}$ Starting with simple $1,5-$ enynes and without internal or external nucleophiles, the racemic gold-catalyzed cycloisomerization was explored simultaneously by several research groups in 2004 . Toste ${ }^{3 a}$ and $\mathrm{Kozmin}^{3 \mathrm{~b}}$ isolated bicyclo[3.1.0]hexenes from 1,5-enyne substrates. Later, Au-catalyzed enantioconvergent kinetic resolution of racemic 1,5-enynes was developed with the use chiral Au(III)-complexes (Scheme 1a). ${ }^{\text {3e }}$ Fürstner developed related gold-catalyzed transformation starting from hydroxylated 1,5-enynes. ${ }^{4 a}$ In the group, enantioselective cycloisomerization of these substrates furnished the corresponding product in up to $90: 10$ enantiomeric ratios (Scheme 1b). ${ }^{4 c}$ In 2005, the Au-catalyzed cyclization/intramolecular addition of $\mathrm{O}$-and $\mathrm{N}$-nucleophiles was described. ${ }^{5 a}$ Many different internal nucleophiles were consecutively used, including phenols and aryls. ${ }^{5}$ The other known reactivity of this class of substrate is the intermolecular nucleophilic addition/cyclization process. ${ }^{6}$ Gagosz developed a diastereoselective hydroxy- and alkoxy-cyclization of 1,5enynes for the synthesis of highly functionalized cyclopentenes. ${ }^{6 a}$ Carbon-nucleophiles were also used in this transformation (Scheme 1c). ${ }^{6 \mathrm{~b}}$ In the framework of the present study, we proposed to explore the first enantioselective gold(I)catalyzed nucleophilic addition/cyclization of achiral and nonfunctionalized 1,5-enyne substrates (Scheme 1d). Initially, the cyclization of the substrate $\mathbf{1} \mathbf{a}$ into the product $\mathbf{3} \mathbf{a}$ has been investigated by using $5 \mathrm{~mol} \%$ of the achiral $\mathrm{Ph}_{3} \mathrm{PAuCl}_{/} \mathrm{AgBF}_{4}$ catalyst, in presence of the para-methoxyphenol $\mathbf{2 a}$, in dichloromethane at $20^{\circ} \mathrm{C}$ (Table 1 , entry 1$)$. The desired racemic cyclopentene derivative $3 a$ was obtained in $80 \%$ isolated yield through an alkoxylation/5-endo-dig cyclization process. ${ }^{9}$

a) Kinetic resolution of 1,5-enynes ${ }^{3 e}$
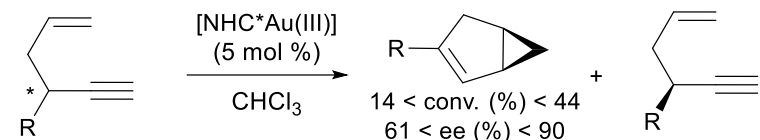

b) Asymmetric cycloisomerization of 3-hydroxy-1,5-enynes ${ }^{4 c}$
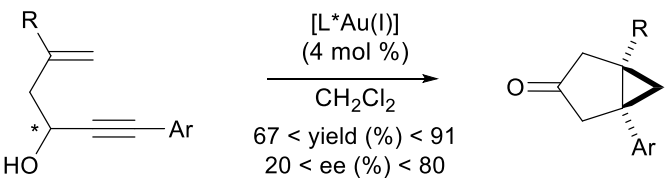

c) Diastereoselective addition of nucleophile/cyclization of 1,5-enynes ${ }^{6 a, b}$

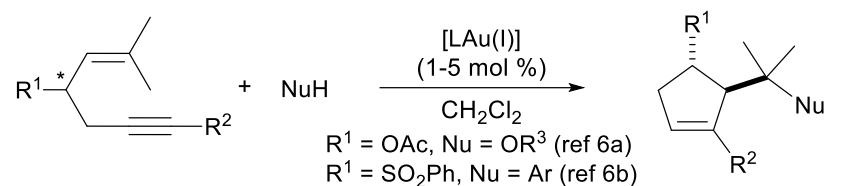

d) This work: enantioselective cyclization/nucleophilic addition

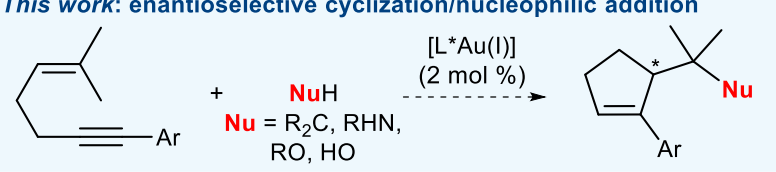

Scheme 1. Gold-catalyzed reactivity of 1,5-enyne substrates.

Subsequently, we focused our attention on the development of an enantioselective variant of this reaction. Several chiral gold(I) complexes were synthesized from commercially available axially chiral diphosphines. The corresponding digold complexes, which usually furnished good level of enantioselectivity in asymmetric cyclization reactions with 1,6enynes, ${ }^{8}$ provided in the present study quite disappointing results (Table 1 , entries $2-7$ ). Indeed, the ( $R$ )-MeO-BIPHEPbigold(I) precatalysts (I-III), after activation with $\mathrm{AgSbF}_{6}$ afforded low isolated yields and enantiomeric ratios (up to 68:32 er, entries 2-4). Other digold(I) complexes of atropochiral SEGPHOS-diphosphines (IV-VI), triggered slightly better enantioselectivities (entries 5-7, up to 75:25 er). We next turned our attention to the TADDOL phosphoramidite-AuCl monogold catalyst (VII), developed by Fürstner. ${ }^{10} \mathrm{~A}$ much more interesting result was quickly obtained with $\mathrm{AgSbF}_{6}$ as activator, with a 87.5:12.5 enantiomeric ratio (entry 8), with however a low yield. In order to find the best compromise between yield and enantioselectivity, we next screened different silver salts 
(entries 9-12). The reaction reached $84 \%$ yield and 88.5:11.5 er using $\mathrm{AgPF}_{6}$ (entry 12). Finally, a solvent screening revealed that 1,2-dichloroethane was the best solvent for this reaction, giving the chiral derivative $3 a$ in $80 \%$ isolated yield and 93:7 er, at -20 ${ }^{\circ} \mathrm{C}$ (entry 13-14). The decrease of the reaction temperature to $40{ }^{\circ} \mathrm{C}$ did not improve this result (entry 15 ). Interestingly, using the same reaction condition, the catalytic loading of the active gold catalyst could be decreased to $2 \mathrm{~mol} \%$, while keeping a very good result both in terms of isolated yield and enantioselectivity ( $81 \%$ yield, 93:7 er, entry 16). Under the optimized conditions, the substrate scope was then surveyed by employing different aryl-substituted 1,5-enyne substrates 1 and nucleophiles 2 (Scheme 2). The enantioselective catalytic reaction was found to tolerate both electron-donating and electron-withdrawing groups on both reactants. The electronic nature and substitution pattern of substituents can however slightly influence the formation and the enantioselectivity of products 3. Starting with 4-methoxyphenol as nucleophile, different substituents on the aryl ring of substrate 1 were tested (Scheme 2a). Compared to product 3a, 2-methoxybenzenesubstituted substrate gave in this transformation low results in term of isolated yield, by keeping high er (compound 3b, $37 \%$ yield, 96:4 er). If good yields were obtained in the formation of products $\mathbf{3 c}$ and $\mathbf{3 d}$, the enantioselectivity depends of the electronic properties of the substrates. Different aromatic alcohols were used as nucleophiles, giving the corresponding cyclization/nucleophilic addition products in moderate to excellent yields (compounds $\mathbf{3 e - 3 g}$, $77-99 \%$ yields) and up to 91:9 er (Scheme 2b). We then modified the nature of the oxygenated nucleophile (Scheme 2c). The cyclopentene derivatives $\mathbf{3} \mathbf{h}-\mathbf{3} \mathbf{j}$ were obtained in moderate to good yields and enantiomeric ratios, with the use of allyl alcohol, propargyl alcohol and methanol as nucleophiles. Interestingly, when water was used, compounds $\mathbf{3 k - 3 n}$ were isolated in $61-98 \%$ yields and up to 97:3 er (Scheme $2 \mathrm{~d}$ ). Amine derivatives ( $p-\mathrm{NO}_{2-}$ aniline and ethyl carbamate) could be also used and the corresponding compounds 3o-p were isolated in $66-81 \%$ yields and up to $93: 7$ er (Scheme 2e). Interestingly, carbon nucleophiles could be used in our methodology. With 1methylindole or $N$-unprotected indole, the addition occurred at C3-position of the indole in $78-91 \%$ yield (compounds $\mathbf{3 q - 3 t}$, Scheme $2 \mathrm{f}$ ). In this case, even the use of sterically hindered substrate gave product $3 \mathrm{~s}$ in high yield and 96:4 er. The reaction has been scaled up to a $1 \mathrm{mmol}$ scale for the formation of compound 3c. A slight decrease in both the yield and the enantioselectivity was noted ( $50 \%$ yield, $91: 9 \mathrm{er}$ ), compared to the result at a lower scale. Some other nucleophiles such as bulky phenol derivatives and heteroaromatic or aromatic substrates such as 2,5-dimethylfuran and 1,3,5trimethoxybenzene were not compatible with this transformation. Finally, to demonstrate a possible postfunctionalization of the products, hydrogenation of $\mathbf{3 c}$ furnished the chiral cyclopentane derivative in $90 \%$ yield and high diastereoselectivity ( $d r>20 / 1$, see ESI for details).
Table 1. Optimization of the enantioselective gold(I)-catalyzed cyclization/nucleophilic addition.

[Lul/Ag
entry

${ }^{a}$ Isolated yield. ${ }^{b}$ Determined by SFC on a chiral stationary phase. ${ }^{c} 5 \mathrm{~mol} \% .{ }^{d}$ 1,2-Dichloroethane as solvent. ${ }^{e}-20{ }^{\circ} \mathrm{C}, 24 \mathrm{~h}^{f}{ }^{f}-40{ }^{\circ} \mathrm{C}, 24 \mathrm{~h}^{\circ}{ }^{g} 2 \mathrm{~mol} \%$ of (VII) and $\mathrm{AgPF}_{6}$, in 1,2-dichloroethane at $-20{ }^{\circ} \mathrm{C}, 24 \mathrm{~h}$.

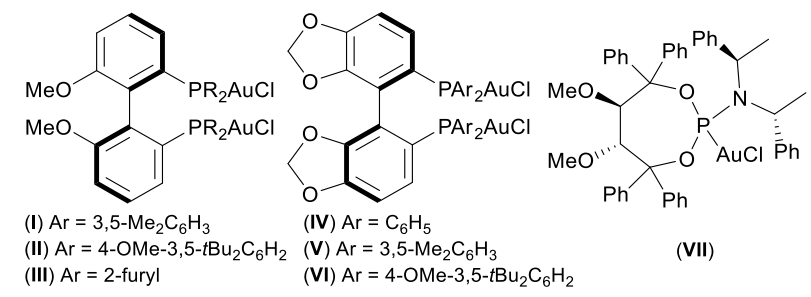

The mechanisms of both the gold-catalyzed 1,5-enyne cycloisomerization and the reaction of 1,5-enynes with alcohol in presence of $\mathrm{Au}(\mathrm{I})$-catalyst have been well documented. ${ }^{11}$ This mechanism is sumarized in Scheme 3.

After chloride abstraction with silver salt, ${ }^{12}$ the corresponding cationic $\operatorname{gold}(\mathrm{I})$ catalyst activated the alkyne function of substrate 1, which promoted the nucleophilic addition of the pendant olefin to form the cationic intermediate. The latter can be considered as a hybrid resonance between carbenoid and carbocation. This intermediate can be trapped in the presence of an external nucleophile 2. Finally, protodeauration produced the target compound $\mathbf{3}$ and regenerated the cationic gold complex. 

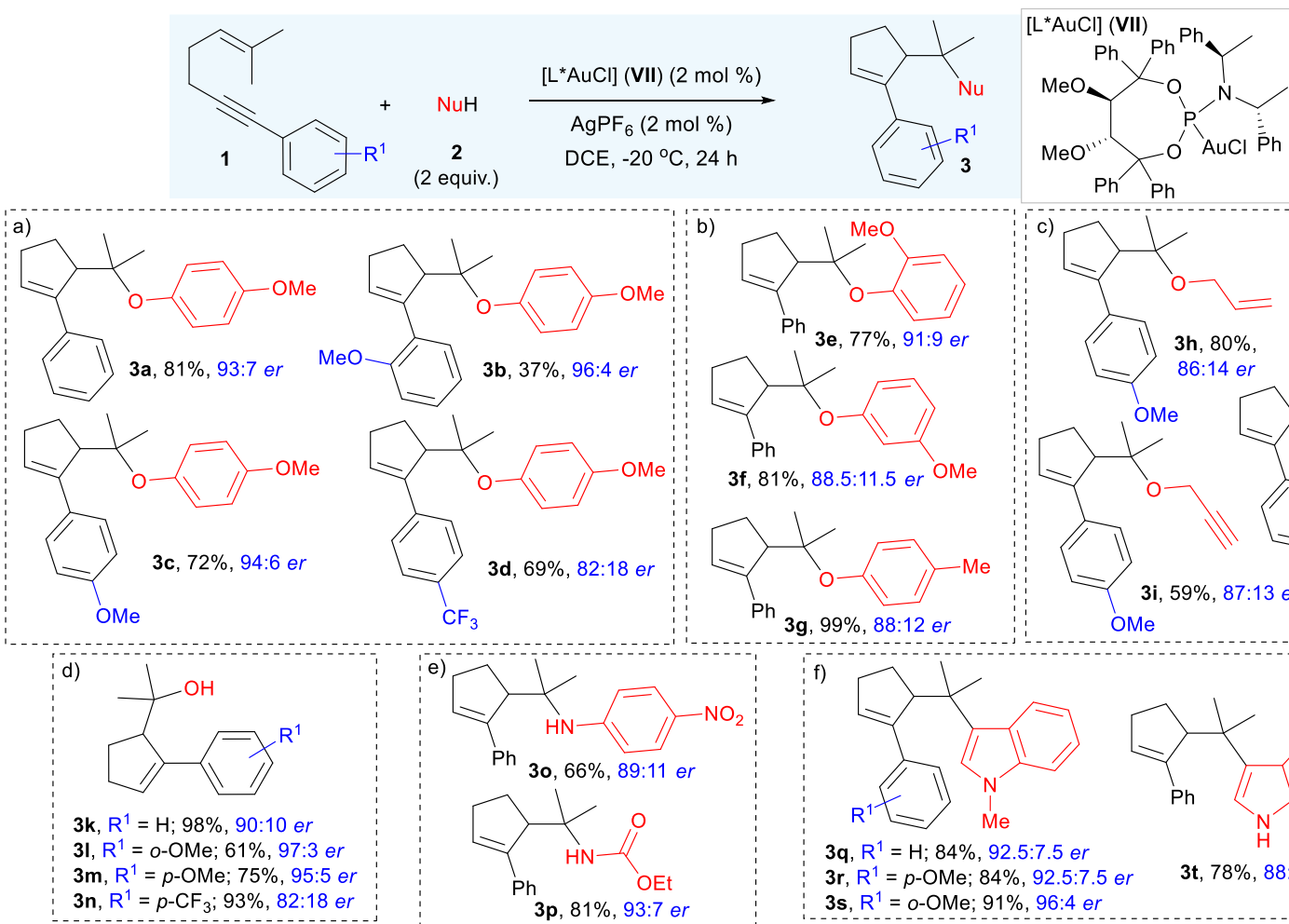

$\mathrm{MeO}$

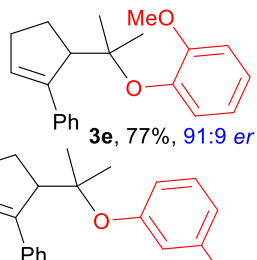

$\mathrm{Ph}$

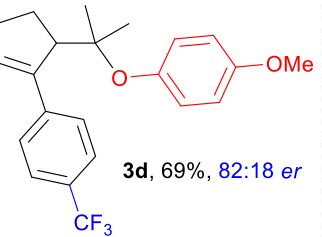

3f, $81 \%, 88.5: 11.5$ er $\mathrm{OMe}$
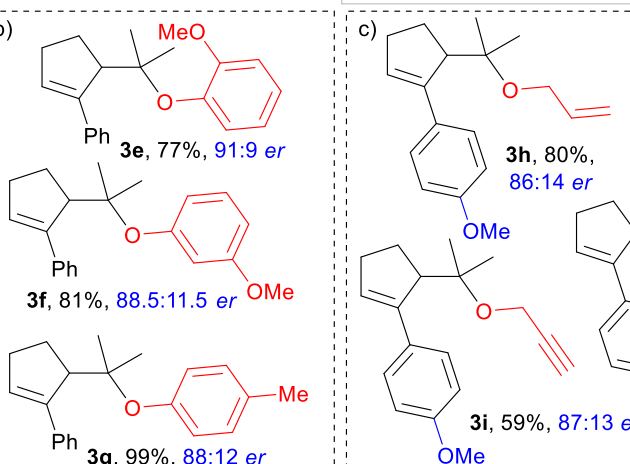

$3 \mathrm{~h}, 80 \%$,

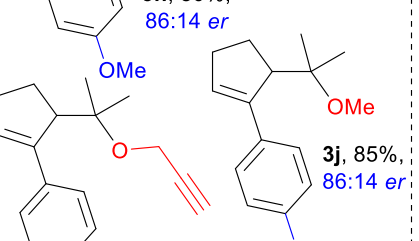

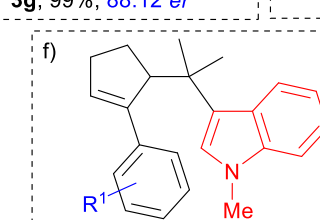

3q, $\mathrm{R}^{1}=\mathrm{H} ; 84 \%, 92.5: 7.5$ er $3 r, \mathrm{R}^{1}=p-\mathrm{OMe} ; 84 \%, 92.5: 7.5 \mathrm{er}$ 3s, $\mathrm{R}^{1}=0-\mathrm{OMe} ; 91 \%, 96: 4$ er

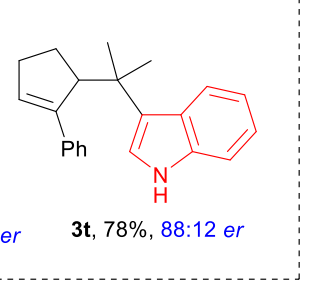

Scheme 2. Reaction scope of the asymmetric gold(I)-catalyzed intermolecular addition of nucleophile/cyclization of 1,5-enyne substrates.

Using the chiral gold-catalyst $(R, R, R, R)$-VII, the product $(R)-3 \mathrm{c}$ was formed, as confirmed by $\mathrm{X}$-ray crystal structure studies. The cyclization of a model 1,5-enyne $\mathbf{A}$ into the putative diastereomeric cyclopropylcarbenoids $\mathbf{B}$ that precedes the nucleophilic addition has been studied by means of DFT computations using the Gaussian 09 software package (Scheme 4 and ESI for details). The best option is clearly that leading to $(S, R)-\mathbf{B}$, both kinetically $\left(\Delta \Delta G^{\ddagger}=-1.8 \mathrm{kcal} / \mathrm{mol}\right)$ and thermodynamically $(\Delta \Delta G=-2.5 \mathrm{kcal} / \mathrm{mol})$. As the phenyl group

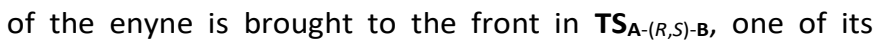
hydrogen comes closer to one Ph group of the Taddol moiety than in the case of $\mathbf{T S}_{\mathrm{A}-(S, R)-\mathbf{B}}$. This is one of the steric factors that explain the higher free energy of activation in the case of $(R, S)$ B and its lower stability. In the cyclopropylcarbenoids B, similarly to those described in the case of some 1,6 -enynes, one of the cyclopropane bond is elongated to as much as $1.70 \AA$, as a result of a great contribution of the gem-dimethyl substituents to the stabilization of the cationic resonance form. Addition of the nucleophile is thus expected at the carbon bearing these two methyl groups (Scheme 4, right). ${ }^{11 b} \mathrm{~A}$ possible interaction between the nucleophiles (especially

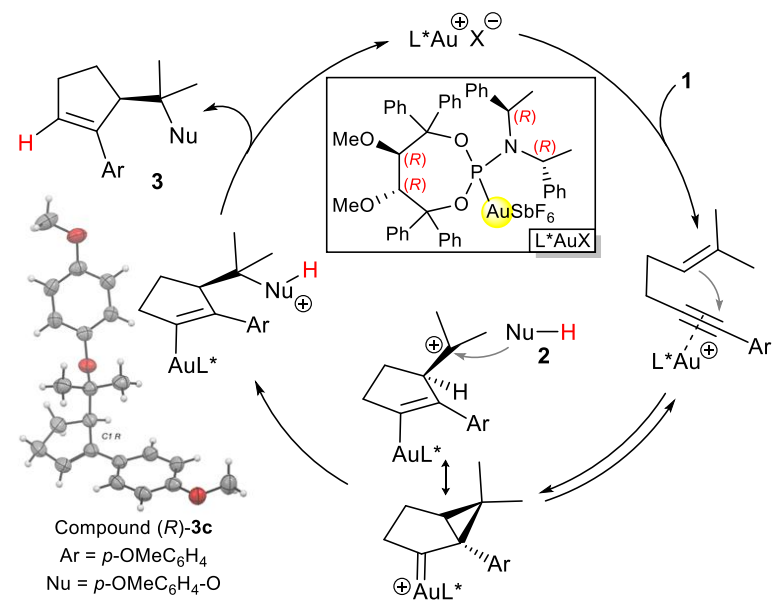

Scheme 3. Mechanistic proposal and X-ray crystal structure of product $(R)-3 c$ (thermal ellipsoids at 50\% probability level).

alcohols and amines) with the chiral gold catalyst via $\mathrm{H}$-bonding may occur and could lead to a slight modification of the chiral ligand. ${ }^{13}$ That could explain the observed differences in enantioselectivity, with the use of different nucleophiles.

In conclusion, we have reported herein the first enantioselective $\mathrm{Au}(\mathrm{I})$-promoted $\mathrm{O}-, \mathrm{N}$ - and $\mathrm{C}$-nucleophile addition/cyclization of simple 1,5-enynes. This transformation provided a straightforward access to functionalized cyclopentenes in good to high yields with high levels of 
enantioselectivities (up to 96:4 er). The stereodetermining step has been investigated by DFT calculations.

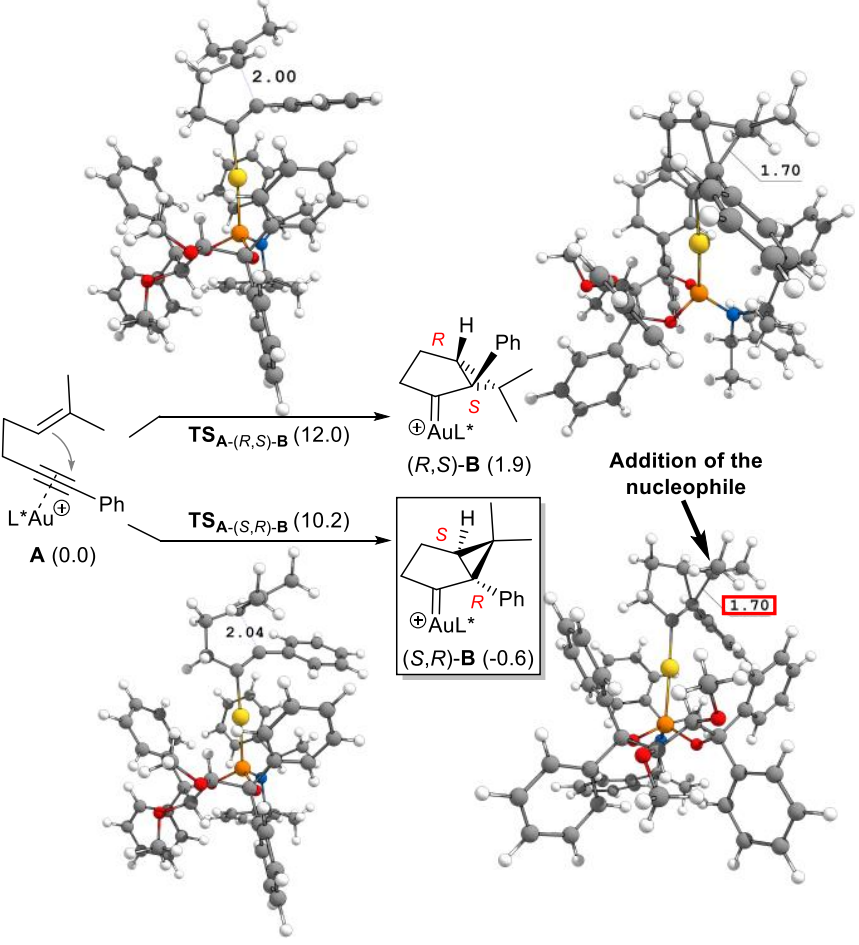

Scheme 4. Free energies $\left(\Delta G_{253}, \mathrm{kcal} / \mathrm{mol}\right)$ and selected distances $(\AA ̊)$ of the computed species.

We thank the CSC (China Scholarship Council) for PhD grant to X. H., Paris-Saclay University, Ecole Polytechnique and CNRS for financial support. We used the CINES OCCIGEN cluster. There are no conflicts of interest to declare.

\section{Notes and references}

1 (a) R. Dorel and A. M. Echavarren, Chem. Rev., 2015, 115 9028; (b) Y. Wei and M. Shi, ACS Catalysis, 2016, 6, 2515; (c) D. Pflästerer and A.S.K. Hashmi, Chem. Soc. Rev., 2016, 45, 1331; (d) A. M. Asiri and A. S. K. Hashmi, Chem. Soc. Rev., 2016, 45, 4471; (e) M. Marín-Luna, O. Nieto Faza and C. Silva López, Front. Chem., 2019, 7, 296.

2 (a) A. Marinetti, H. Jullien and A. Voituriez, Chem. Soc. Rev., 2012, 41, 4884; (b) W.-W. Zi and F.-D. Toste, Chem. Soc. Rev., 2016, 45, 4567; (c) Y. Li, W. Li and J. Zhang, Chem. Eur. J., 2017, 23, 467.

3 (a) M. R. Luzung, J. P. Markham and F. D. Toste, J. Am. Chem. Soc., 2004, 126, 10858; (b) L. Zhang and S. A. Kozmin, J. Am. Chem. Soc., 2004, 126, 11806; (c) Y. Horino, T. Yamamoto, K. Ueda, S. Kuroda and F. D. Toste, J. Am. Chem. Soc., 2009, 131, 2809; (d) J. P. Reeds, A. C. Whitwood, M. P. Healy and I. J. S. Fairlamb, Chem. Commun., 2010, 46, 2046; (e) P. T. Bohan and F. D. Toste, J. Am. Chem. Soc., 2017, 139, 11016; (f) H. Zheng, R. J. Felix and M. R. Gagné, Org. Lett., 2014, 16, 2272; (g) G.Q. Chen, W. Fang, Y. Wei, X.-Y. Tang and M. Shi Chem. Sci., 2016, 7, 4318.

4 (a) V. Mamane, T. Gress, H. Krause and A. Fürstner, J. Am. Chem. Soc., 2004, 126, 8654; (b) F. Gagosz, Org. Lett., 2005, 7, 4129; (c) Z. Wu, P. Retailleau, V. Gandon, A. Voituriez and A. Marinetti, Eur. J. Org. Chem., 2016, 70; (d) G. Abbiati, A. Arcadi, G. Bianchi, S. Di Giuseppe, F. Marinelli and E. Rossi, J. Org. Chem., 2003, 68, 6959; (e) H. Imase, K. Noguchi, M.
Hirano and K. Tanaka, Org. Lett., 2008, 10, 3563; (f) C. Jiang, M. Xu, S. Wang, H. Wang and Z.-J. Yao, J. Org. Chem., 2010, 75, 4323; (g) S. T. Staben, J. J. Kennedy-Smith and F. D. Toste, Angew. Chem., Int. Ed., 2004, 43, 5350; (h) E. C. Minnihan, S. L. Colletti, F. D. Toste and H. C. Shen, J. Org. Chem., 2007, 72, 6287; (i) J. F. Brazeau, S. Zhang, I. Colomer, B. K. Corkey and F. D. Toste, J. Am. Chem. Soc., 2012, 134, 2742. For Pt-catalysis, see: (j) Y. Harrak, C. Blaszykowski, M. Bernard, K. Cariou, E. Mainetti, V. Mouriès, A.-L. Dhimane, L. Fensterbank and M. Malacria, J. Am. Chem. Soc., 2004, 126, 8656.

5 (a) L. Zhang and S. A. Kozmin, J. Am. Chem. Soc., 2005, 127, 6962; (b) B. D. Sherry, L. Maus, B. N. Laforteza and F. D. Toste, J. Am. Chem. Soc., 2006, 128, 8132; (c) S. Böhringer and F. Gagosz, Adv. Synth. Catal., 2008, 350, 2617; (d) P. Y. Toullec, T. Blarre, V. Michelet, Org. Lett., 2009, 11, 2888; (e) V. LópezCarrillo, N. Huguet, A. Mosquera and A. M. Echavarren, Chem. Eur. J., 2011, 17, 10972; (f) N. Huguet and A. M. Echavarren, Synlett, 2012, 23, 49; (g) A. Pradal, Q. Chen, P. Faudot dit Bel, P. Y. Toullec and V. Michelet, Synlett, 2012, 23, 74.

6 (a) A. K. Buzas, F. M. Istrate and F. Gagosz, Angew. Chem., Int. Ed., 2007, 46, 1141; (b) C. H. M. Amijs, V. López-Carrillo, M. Raducan, P. Pérez-Galán, C. Ferrer and A. M. Echavarren, J. Org. Chem., 2008, 73, 7721; (c) K. Speck, K. Karaghiosoff and T. Magauer, Org. Lett., 2015, 17, 1982.

7 (a) T. Shibata, Y. Ueno and K. Kanda Synlett, 2006, 411; (b) C. Michon, S. Liu, S. Hiragushi, J. Uenishi and M. Uemura, Tetrahedron, 2008, 64, 11756; (c) A. Martínez, P. GarcíaGarcía, M. A. Fernández-Rodríguez, F. Rodríguez and R. Sanz, Angew. Chem., Int. Ed., 2010, 49, 4633; (d) A. M. Sanjuán, M. A. Rashid, P. García-García, A. Martínez Cuezva, M. A. Fernández-Rodríguez, F. Rodríguez and R. Sanz, Adv. Synth. Catal., 2013, 355, 1955; (e) K. Ji, Z. Zheng, Z. Wang and L. Zhang, Angew. Chem., Int. Ed., 2015, 54, 1245.

8 (a) M. P. Muñoz, J. Adrio, J. C. Carretero and A. M. Echavarren, Organometallics, 2005, 24, 1293; (b) C.-M. Chao, E. Genin, P. Y. Toullec, J.-P. Genet and V. Michelet, J. Organomet. Chem., 2009, 694, 538; (c) C.-M. Chao, M. R. Vitale, P. Y. Toullec, J.-P. Genêt and V. Michelet, Chem. Eur. J., 2009, 15, 1319; (d) A. Z. Gonzalez, D. Benitez, E. Tkatchouk, W. A. Goddard, III and F. D. Toste, J. Am. Chem. Soc., 2011, 133, 5500; (e) A. Pradal, C.M. Chao, M. R. Vitale, P. Y. Toullec and V. Michelet, Tetrahedron, 2011, 67, 4371; (f) N. Delpont, I. Escofet, P. Perez-Galan, D. Spiegl, M. Raducan, C. Bour, R. Sinisi and A. M. Echavarren, Catal. Sci. Technol., 2013, 3, 3007; (g) P. Aillard, P. Retailleau, A. Voituriez and A. Marinetti, Chem. Eur. J., 2015, 21, 11989; (h) P. Aillard, D. Dova, V. Magné, P. Retailleau, S. Cauteruccio, E. Licandro, A. Voituriez and A. Marinetti, Chem. Commun., 2016, 52, 10984.

9 In ref. 6a, Gagosz reported a single example with nonhydroxylated 1,5-enyne substrate, with the use of methanol as external nucleophile.

10 (a) H. Teller, S. Flügge, R. Goddard and A. Fürstner, Angew. Chem., Int. Ed., 2010, 49, 1949; (b) H. Teller, M. Corbet, L. Mantilli, G. Gopakumar, R. Goddard, W. Thiel and A. Fürstner, J. Am. Chem. Soc., 2012, 134, 15331.

11 (a) Y. Liu, D. Zhang and S. Bi, J. Phys. Chem. A, 2010, 114, 12893; (b) A. Ariafard, E. Asadollah, M. Ostadebrahim, N. A. Rajabi and B. F. Yates, J. Am. Chem. Soc., 2012, 134, 16882; (c) T. Fan, X. Chen, J. Sun and Z. Lin, Organometallics, 2012, 31, 4221.

12 M. Jia, M. Bandini, ACS Catal. 2015, 5, 1638.

13 For gold(I)/menthol cooperative catalysis, see : O. Kanno, W. Kuriyama, Z. J. Wang and F. D. Toste, Angew. Chem., Int. Ed., 2011, 50, 9919. Furthermore, with the use of different nucleophiles, both the solvent polarity and dielectric constant could be different and have some impact on the reaction outcome. 